\title{
Isolated adrenal metastasis of hepatocellular carcinoma (HCC) post liver transplantation: A rare entity
}

\author{
Jatin Agrawal*, Praveen Kumar, Anil Arora and Ashish Kumar \\ Institute of Liver, Gastroenterology and Panceatico-Biliary Sciences, Sir Gangaram hospital, New Delhi, India
}

\begin{abstract}
Extra hepatic recurrence of hepatocellular carcinoma (HCC) after liver transplant is seen only in 10-15\% cases. Usual site for recurrence is lung, bones and lymph nodes. Adrenal metastasis is rare and usually seen along with other organs recurrence. Isolated adrenal metastasis from HCC after liver transplant is rare entity. Surgical resection of isolated adrenal recurrence is described in few case reports with variable outcome. Here, we also report a case of isolated adrenal recurrence of HCC after liver transplant. Patient was successfully treated him with adrenalectomy. Post adrenalectomy 3 years follow up showed good overall survival without recurrence.
\end{abstract}

\section{Introduction}

Hepatocellular carcinoma (HCC) is among leading cause of cancer related mortality. With advances in diagnostic and treatment modality, curative treatment in form of liver transplantation (LT) is done if detected early in course. Though recurrence is uncommon, it is seen in $10-15 \%$ of all LTs for HCC with median time from LT to recurrence were 13 months. Majority of recurrence are extrahepatic including lung, bones, lymph nodes and rarely adrenal and brain [1]. Overall adrenal recurrence constitutes $8-16 \%$ of extrahepatic metastasis and among these only few cases are of isolated adrenal recurrence. Median overall survival with and without treatment of 22 months and 12 months respectively was seen in different studies [2,3]. Hence literature on isolated adrenal metastasis is variable with no specific defined treatment. We report a rare case of isolated adrenal recurrence post liver transplant which was successfully treated with adrenalectomy and adjuvant oral Lenvatinib with 3years follow up.

\section{Case Report}

64 years old male Indian came with complaint of persistent fever and lower abdominal pain for last 7 days. He underwent DDLT 3 years back for hepatitis B related cirrhosis with BCLC stage B hepatocellular carcinoma (HCC). Post transplantation he was on steroid, tacrolimus and tenofovir. His HBV DNA was undetected before transplantation and after that in follow up. General and systemic examination was unremarkable except he was febrile with temperature of $101 \mathrm{~F}$. Laboratory investigations showed his hemoglobin $10.3 \mathrm{~g} / \mathrm{dL}$, WBC $8000 \mathrm{u} / \mathrm{L}(\mathrm{N} 90 \%$, L 10\%), platelets $260,000 \mathrm{u} / \mathrm{L}$, serum creatinine $0.8 \mathrm{mg} / \mathrm{dL}$, sodium $132 \mathrm{meq} / \mathrm{L}$, potassium

$4.5 \mathrm{meq} / \mathrm{L}$, corrected calcium $9.8 \mathrm{mg} / \mathrm{dL}$, Phosphate $3.9 \mathrm{mg} / \mathrm{dL}$, total bilirubin $0.8 \mathrm{mg} / \mathrm{dL}$, SGOT/SGPT 16/18, Albumin $3.0 \mathrm{gm} / \mathrm{dL}$, protein $5.4 \mathrm{mg} / \mathrm{dL}$ and INR 1.2. His serum AFP level was very high 9152. Subsequently CT abdomen was done which showed large heterogenous enhancing mass in right suprarenal region measuring $6.5 \mathrm{~cm} \mathrm{x} 7.5 \mathrm{~cm} \mathrm{x}$ $8.3 \mathrm{~cm}$ with normal appearing post -transplant liver (Figures $1 \mathrm{a}$ and $1 \mathrm{~b}$ ). With this there was suspicious of adrenal metastasis, hence EUS guided fine needle aspiration of adrenal mass was done. Cytology with immunohistochemistry (IHC) revealed metastatic HCC with hep par positivity (Figure 2). His serum cortisol levels were normal. Further PET scan was done which showed FDG avid lesion in right supra renal region and no other FDG avid lesion elsewhere. This confirms diagnosis of isolated adrenal metastatic hepatocellular carcinoma (HCC). As disease was localized to adrenal with otherwise no lesion elsewhere, he underwent right adrenalectomy without any post-operative

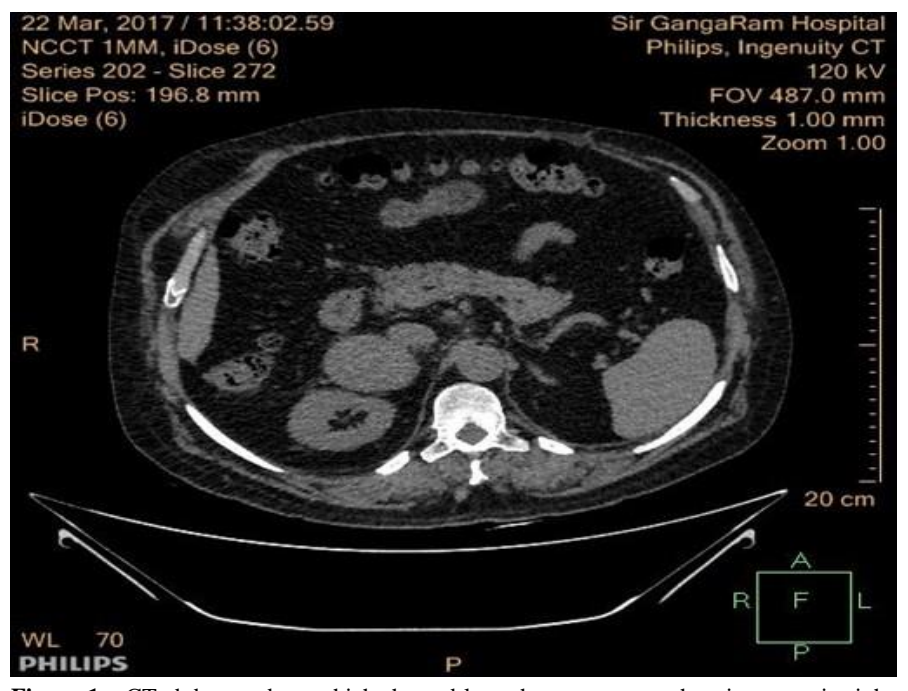

Figure 1a. CT abdomen done which showed large heterogenous enhancing mass in right suprarenal region measuring $6.5 \mathrm{~cm} \times 7.5 \mathrm{~cm} \times 8.3 \mathrm{~cm}$

*Correspondence to: Agrawal J, Institute of Liver, Gastroenterology and Panceatico-Biliary Sciences, Sir Gangaram hospital, New Delhi, India, Tel: 7878474430; E-mail: jatinagrawal1989@gmail.com

Key words: hepatocellular carcinoma, adrenal metastasis, adrenalectomy, liver transplantation

Received: May 25, 2021; Accepted: June 08, 2021; Published: June 11, 2021 


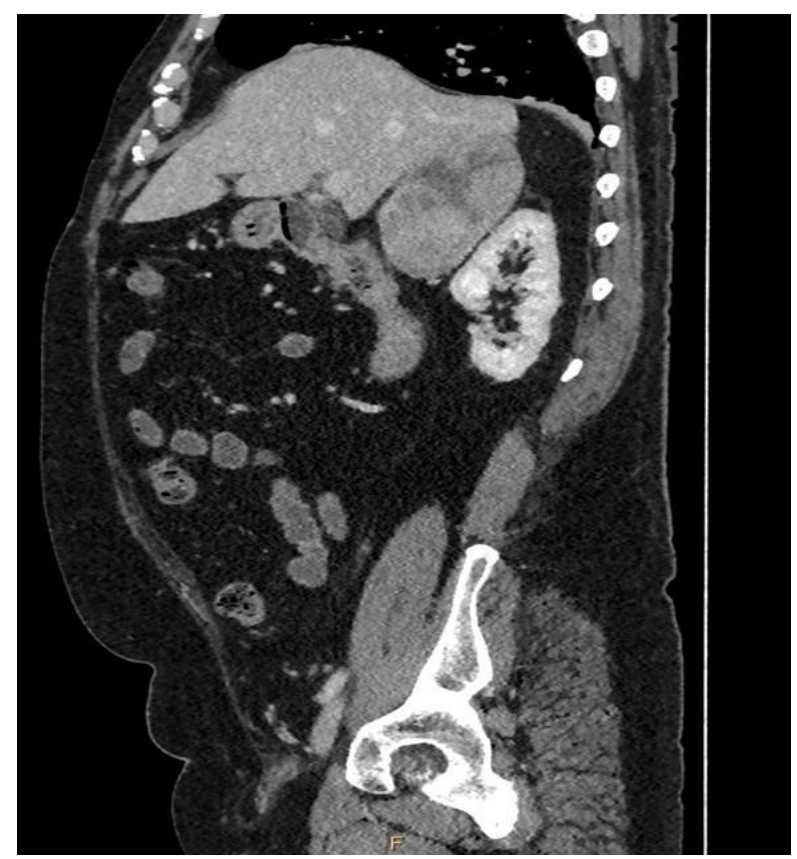

Figure 1b. CT abdomen with normal appearing post -transplant liver

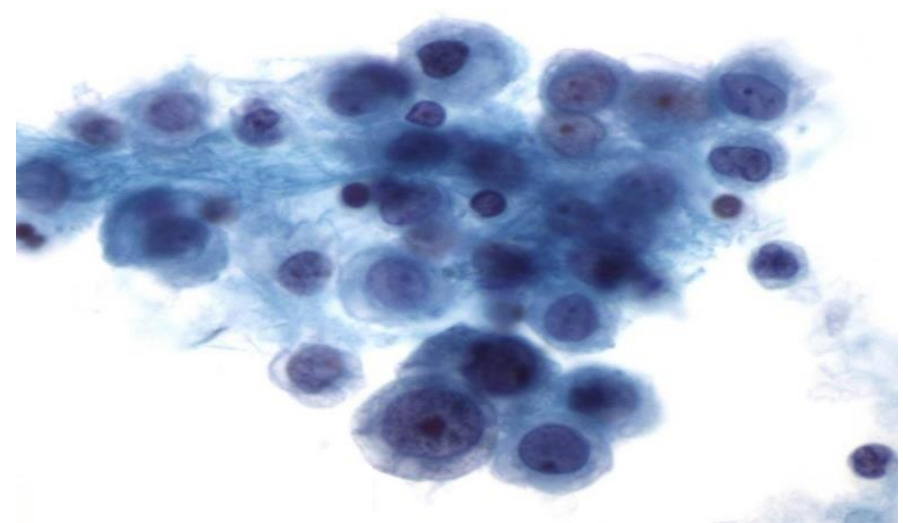

Figure 2. Cytology with immunohistochemistry (IHC) revealed metastatic HCC with hep par positivity

complications. Patient symptomatically improved after surgery. On discharge he was started on oral lenvatinib which he tolerated well. After one year of follow up his serum AFP reduced to $4 \mathrm{ng} / \mathrm{ml}$ and imaging did not show any new recurrence. Even at 3 years follow up, patient was recurrence free on oral Lenvatinib.

\section{Discussion}

Data on hepatocellular carcinoma in India suggest incidence on cirrhosis of $1.6 / 100$ person per year (male predominant) [4]. The risk is higher in cirrhosis due to viral etiologies including hepatitis B and C. Liver transplant for HCC provide a curative option with long term survival if done within milan criteria. Recurrence is uncommon and that of isolated adrenal involvement is rare, only seen in some case reports [5]. Risk factors for recurrence includes positivity for viral markers, larger tumour diameter $(>5 \mathrm{~cm})$, multiple tumour nodules $(>3)$, presence of vascular tumour invasion and elevated tumour markers (serum AFP $>1000 \mathrm{ng} / \mathrm{ml}$ ) [3]. The median time for adrenal recurrence seen in a study was $30.8 \pm 19.4$ months after diagnosis of primary HCC [6]. In our case also the time for adrenal recurrence was around 48 months. Only one case report in literature has shown longer median time of recurrence of 138 months [7]. Such late recurrences are suggestive of less aggressive tumor biology compare to early recurrence within 1st year of LT. The largest diameters of isolated adrenal metastatic lesion were reported are in range of 27 and $44 \mathrm{~mm}$, in our case it is $83 \mathrm{~mm}$. This shows the asymptomatic and slow growing nature of adrenal recurrence. Thus, routine screening post liver transplantation for recurrence is advised to detect them at early stage where curative resections are possible.

Different therapeutic strategies like local ablative methods and systemic therapy as well as surgery have been considered for the therapy of adrenal metastasis of HCC. Adrenalectomy provides favorable survival outcome in selected groups with preserved liver function and no tumor evidence elsewhere. In case of adrenal lesion on follow up imaging, tissue diagnosis is required to confirm the metachronous recurrence and imaging including PET scan to rule out another site involvement is recommended before undertaking patient for adrenalectomy [8]. It is safe procedure with mean survival after adrenalectomy $112.4 \pm 25.2$ months and mean time for tumor recurrence 15.8 months [6]. Other groups have also shown similar longterm benefits of adrenalectomy in selected group of patients [9]. In our case the patient is still alive with good performance status without recurrence. Sorafenib or lenvatinib after adrenalectomy has shown some survival benefits and help to reduce the recurrence [10].

In summary we reported a rare entity of isolated metastasis which was successfully treated with adrenalectomy followed by adjuvant targeted therapy. Close surveillance for HCC recurrence post transplantation is key, to detect and effectively treat them early.

\section{Conflict of interest}

None.

\section{Funding source}

None.

\section{Ethical approval}

Not applicable.

\section{Statement of compliance and Clinical Trial Transparency}

Not applicable.

\section{References}

1. de'Angelis N, Landi F, Carra MC, Azoulay D (2015) Managements of recurrent hepatocellular carcinoma after liver transplantation: A systematic review. World $J$ Gastroenterol 21: 11185-11198. [Crossref]

2. Uchino K, Tateishi R, Shiina S, Kanda M, Masuzaki R, et al. (2011) Hepatocellular carcinoma with extrahepatic metastasis: clinical features and prognostic factors. Cancer 117: 4475-4483. [Crossref]

3. Kanda M, Tateishi R, Yoshida H, Sato T, Masuzaki R, et al. (2008) Extrahepatic metastasis of hepatocellular carcinoma: incidence and risk factors. Liver Int Off J Int Assoc Study Liver 28: 1256-1263. [Crossref]

4. Paul SB, Sreenivas V, Gulati MS, Madan K, Gupta AK, et al. (2007) Incidence of hepatocellular carcinoma among Indian patients with cirrhosis of liver: an experience from a tertiary care center in northern India. Indian J Gastroenterol Off J Indian Soc Gastroenterol 26: 274-278. [Crossref]

5. Hwang S, Moon DB, Ahn CS, Kim KH, Ha TY, et al. (2013) Risk-based long- term screening for hepatocellular carcinoma recurrence after living donor liver transplantation. Transplant Proc 45: 3076-3084. [Crossref]

6. Teegen EM, Mogl MT, Pratschke J, Rayes N(2018) Adrenal Metastasis of Hepatocellular Carcinoma in Patients following Liver Resection or Liver Transplantation: Experience from a Tertiary Referral Center. Int J Surg Oncol 2018: 4195076. [Crossref] 
7. Sormaz IC, Yegen G, Akyuz F, Tunca F, Şenyürek YG. Recurrent Hepatocellular Carcinoma in the Right Adrenal Gland 11 Years After Liver Transplantation for Hepatocellular Carcinoma: a Case Report and Literature Review. Indian J Surg 79: 450-454. [Crossref]

8. Chua TC, Morris DL (2012) Exploring the role of resection of extrahepatic metastases from hepatocellular carcinoma. Surg Oncol 21: 95-101. [Crossref]
9. Ha TY, Hwang S, Ahn CS, Kim KH, Lee YJ, et al. (2014) Resection of metachronous adrenal metastasis after liver resection and transplantation for hepatocellular carcinoma. Dig Surg 31: 428-435. [Crossref]

10. Kumar A, Acharya SK, Singh SP, Arora A, Dhiman RK, et al. (2020) 2019 Update of Indian National Association for Study of the Liver Consensus on Prevention, Diagnosis, and Management of Hepatocellular Carcinoma in India: The Puri II Recommendations. J Clin Exp Hepatol 10: 43-80. [Crossref]

Copyright: (C2021 Agrawal J. This is an open-access article distributed under the terms of the Creative Commons Attribution License, which permits unrestricted use, distribution, and reproduction in any medium, provided the original author and source are credited. 